\title{
Analysis of industrial and domestic gases by means of electronic nose
}

\author{
Divya Haridas ${ }^{1}$, Vinay Gupta ${ }^{2}$, \\ ${ }^{1}$ Keshav Mahavidyalaya, University of Delhi, Pitampura, New Delhi 110034, India \\ divya_h14@rediffmail.com \\ ${ }^{2}$ Department of Physics and Astrophysics, University of Delhi, Delhi 110007, India
}

\begin{abstract}
:
In the present study a novel hybrid gas sensor array (E-Nose) composed of $\mathrm{SnO}_{2}$ thin film loaded with different catalyst clusters for sensitive gas discrimination followed by pattern recognition approach is demonstrated. An array of hybrid sensors $\left(\mathrm{SnO}_{2}-\mathrm{Pt}\right.$-custers, $\mathrm{SnO}_{2}-\mathrm{Pd}$-clusters, $\mathrm{SnO}_{2}$-Ag-clusters, $\mathrm{SnO}_{2}$-CuO-clusters) operated at fixed temperatures have been developed for effective discrimination of target gases (LPG, Methane, Ammonia and $\mathrm{H}_{2} \mathrm{~S}$ ). Radar plots and Principal component analysis of the generated patterns of E-Nose showed great discrimination of the target gases. Principal component analysis of the sensing results showed great discrimination of target gases and an array of six sensors are proposed operating at lower temperature $\left(60^{\circ} \mathrm{C}\right.$ or $\left.140^{\circ} \mathrm{C}\right)$ for realization of hybrid class E- Nose exhibiting good performance with low power consumption.
\end{abstract}

Key words: E-Nose, hybrid sensors, Principal component analysis, radar plots.

\section{Introduction}

Recently, there has been an urgent increase in the need for detecting odours, to replace the human job of sensing and quantification. Some of the most important applications fall in the category where human beings cannot afford to risk smelling the substance. Electronic noses have been investigated for detection of such gases in the ambient atmosphere. Electronic noses promised fast and round the clock operation combined with an automated data evaluation system [1-2]. However, not much attention has been paid towards the development of E-Nose for reliable and early detection of explosive gases such as LPG or $\mathrm{CH}_{4}$, which are extensively used as fuel at both the domestic and industrial sites including automobiles. The accidental leakage of these gases may trigger the explosion and cause fires that may lead to severe casualty of human beings and valuable property. The other gases of importance at the domestic or industrial sites are $\mathrm{H}_{2} \mathrm{~S}$ and $\mathrm{NH}_{3}$, which can cause the ill effect on the human health and also demand the development of a reliable sensing device. The presence of any one of these gases in the vicinity of human being is dangerous for the life and health. In the present study, efforts have been made towards the development of $E$ Nose using an array of four metal oxide sensors suitable for detection of the leakage of LPG, $\mathrm{CH}_{4}, \mathrm{NH}_{3}$ and $\mathrm{H}_{2} \mathrm{~S}$ gases at the home or work place. The target gases are chosen keeping in mind the direct consequences in case of their leakage and E-Nose may be useful in giving early warning to avoid any fatal accidents.

\section{Experimental}

$\mathrm{SnO}_{2}$ films $(90 \mathrm{~nm})$ were deposited by $\mathrm{rf}$ reactive sputtering process on corning glass substrate. The ultrathin $(10 \mathrm{~nm})$ metal catalysts of $\mathrm{Pt}, \mathrm{Pd}, \mathrm{Ag}$, and $\mathrm{CuO}$ were loaded in the form of dotted islands on the surface of the sensing $\mathrm{SnO}_{2}$ layer using a shadow mask $(600 \mu \mathrm{m}$ pore size) [3]. The platinum and palladium catalysts were deposited by rf sputtering, whereas silver and copper catalysts were thermally evaporated. The prepared $\mathrm{SnO}_{2}$-catalyst dotted sensors were also heated in air at $300^{\circ} \mathrm{C}$ for 2 $\mathrm{h}$. The annealing treatment was considered sufficient to transform ultrathin copper dotted islands into copper oxide. Thus, loading four different catalyst clusters over $\mathrm{SnO}_{2}$ thin film developed four different sensor structures. The sensor was placed on a temperature controlled heating block and spring loaded platinum contacts were used to measure the sensing response characteristics. Response magnitude and response speed of the sensors were measured as a function of temperature (60$280^{\circ} \mathrm{C}$ ) under exposure to $200 \mathrm{ppm}$ of the above mentioned reducing gases. Sensor response was defined as $R_{a} / R_{g}$, where $R_{g}$ was the resistance in the presence of reducing gas. 


\section{Results and discussion}

E-Nose developed in the present study can be used to discriminate four different gases from the atmosphere using the generated response database of the sensor array for all target gases (LPG, $\mathrm{CH}_{4}, \mathrm{NH}_{3}$ and $\mathrm{H}_{2} \mathrm{~S}$ ) (Fig.1). It is possible to train any pattern recognition system using the available response database of E-Nose and the final product could be used to discriminate and identify unknown target gases. The careful inspection of the response patterns generated by E-Nose having an array of four different sensors (Figs. 1a to 1d) indicates that the temperature of operation is very crucial, and response patterns are highly temperature dependent.
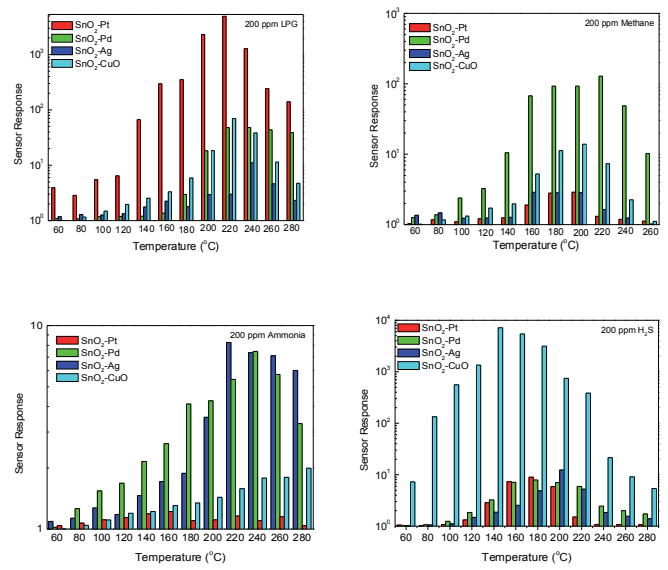

Fig. 1. Pattern generated from E-Nose (array of four sensors) for four different gases (a) LPG, (b) $\mathrm{CH}_{4}$, (c) $\mathrm{NH}_{3}$ (d) $\mathrm{H}_{2} \mathrm{~S}$.

The pattern generated in the present study for each target gas using E-Nose (array of four different sensing elements) is analyzed using radar plots at four specific temperatures $60^{\circ} \mathrm{C}$, $140^{\circ} \mathrm{C}, 220^{\circ} \mathrm{C}$ and $260^{\circ} \mathrm{C}$. The temperature $140^{\circ} \mathrm{C}$ and $220^{\circ} \mathrm{C}$ are the operating temperatures of the stand alone sensing elements used in the array where higher responses for respective gases are expected and a statistically distributed pattern is obtained. The other two temperatures $60^{\circ} \mathrm{C}$ and $260^{\circ} \mathrm{C}$ are the two extreme in the temperature range used in present study. Figure 2(a) to 2(d) shows the radar plots of the hybrid sensor array operated at $60^{\circ} \mathrm{C}$ temperature for the four target gases respectively.

A simple inspection of the radar plots (Fig. 2a to 2d) shows that the possible identification amongst the gases can be achieved since the "finger print" for each gas is unique. The radar plots of hybrid sensor array are well defined even at lower temperature $\left(60^{\circ} \mathrm{C}\right)$. Therefore a library of such "finger print" could be generated using the hybrid-class E- Nose (array of four different sensing elements operating at fixed temperatures) and may be utilized for the discrimination of gases in real field.
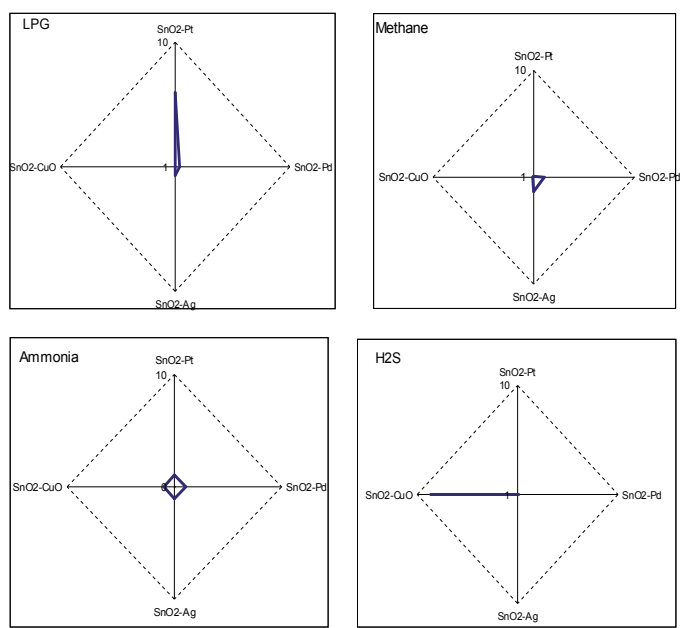

Fig. 2. Radar plots of the hybrid sensor array operated at $60^{\circ} \mathrm{C}$ for the four target gases (a) $L P G$ (b) Methane (c) Ammonia and (d) $\mathrm{H}_{2} \mathrm{~S}$

PCA is a powerful technique of identifying patterns in data, and is used mainly to reduce the dimensionality of a data set from a feature (gas sensor), without much loss of information [4]. PCA analyzes the data by transforming 'interdependent' variables into 'uncorrelated' orthogonal set of variables called Principal Components (PCs). The cumulative variances of PC1 and PC2 for all hybrid-class E Noses are observed to be high (83\%-97\%). Generally, variance more than $80 \%$ is considered good to retain the originality of the data [5], therefore the PCA analysis for hybrid E-Nose in the present study is very good and the loss of information during reduction in dimensionality is expected to be very less. The correlation matrix of hybrid sensors array operating at four temperatures $60^{\circ} \mathrm{C}, 140^{\circ} \mathrm{C}, 220^{\circ} \mathrm{C}$ and $260^{\circ} \mathrm{C}$ are shown respectively in Table $1 \mathrm{~A}$ to $1 \mathrm{D}$.

Tab. 1A:Correlation matrix of hybrid-class E-Nose operated at $60^{\circ} \mathrm{C}$

\begin{tabular}{|l|l|l|l|l|}
\hline \multicolumn{5}{|c|}{ Correlation Matrix } \\
\hline & Pt1 & Pd1 & Ag1 & CuO1 \\
\hline Pt1 & 1.000 & 0.742 & $\mathbf{0 . 8 2 7}$ & -0.410 \\
\hline Pd1 & - & 1.000 & $\mathbf{0 . 9 9 0}$ & -0.621 \\
\hline Ag1 & - & - & 1.000 & -0.624 \\
\hline CuO1 & - & - & - & 1.000 \\
\hline
\end{tabular}


Tab. 1B: Correlation matrix of hybrid-class E-Nose operated at $140^{\circ} \mathrm{C}$

\begin{tabular}{|c|c|c|c|c|}
\hline \multicolumn{5}{|c|}{ Correlation Matrix } \\
\hline & Pt2 & Pd2 & Ag2 & CuO2 \\
\hline Pt2 & 1.000 & -0.331 & -0.769 & 0.437 \\
\hline Pd2 & - & 1.000 & -0.344 & 0.076 \\
\hline Ag2 & - & - & 1.000 & -0.419 \\
\hline $\mathrm{CuO} 2$ & - & - & - & 1.000 \\
\hline
\end{tabular}

Tab. 1C: Correlation matrix of hybrid-class E-Nose operated at $220^{\circ} \mathrm{C}$

\begin{tabular}{|l|l|l|l|l|}
\hline \multicolumn{5}{|c|}{ Correlation Matrix } \\
\hline & Pt3 & Pd3 & Ag3 & CuO3 \\
\hline Pt3 & 1.000 & -0.233 & $\mathbf{0 . 9 7 1}$ & -0.168 \\
\hline Pd3 & - & 1.000 & -0.419 & -0.426 \\
\hline Ag3 & - & - & 1.000 & 0.046 \\
\hline CuO3 & - & - & - & 1.000 \\
\hline
\end{tabular}

Tab. 1D: Correlation matrix of hybrid-class E-Nose operated at $260^{\circ} \mathrm{C}$

\begin{tabular}{|l|l|l|l|l|}
\hline \multicolumn{5}{|l|}{ Correlation Matrix } \\
\hline & Pt4 & Pd4 & Ag4 & CuO4 \\
\hline Pt4 & 1.000 & $\mathbf{0 . 8 4 2}$ & $\mathbf{1 . 0 0 0}$ & 0.525 \\
\hline Pd4 & - & 1.000 & $\mathbf{0 . 8 4 6}$ & 0.151 \\
\hline Ag4 & - & - & 1.000 & 0.530 \\
\hline CuO4 & - & - & - & 1.000 \\
\hline
\end{tabular}

The sensor structures having $\mathrm{Pt}$ and $\mathrm{Ag}$ clusters have strong dependence on PC1 at all operating temperature except $140^{\circ} \mathrm{C}$ and are highly interrelated (Table $1 \mathrm{~A}$ to $1 \mathrm{D}$ ) due to their high correlation coefficient $(>0.827)$. From Table $1 \mathrm{~B}$, it can be concluded that all sensing elements are highly uncorrelated for hybrid-ENose operating at $140^{\circ} \mathrm{C}$. Therefore hybrid ENose at $140^{\circ} \mathrm{C}$ temperature is able to discriminate the four target gases efficiently using all sensing elements in the array. Sensor with $\mathrm{Pd}$ and $\mathrm{Ag}$ clusters are highly interrelated at $60^{\circ} \mathrm{C}$ and $260^{\circ} \mathrm{C}$ (Table $1 \mathrm{~A}$ and $1 \mathrm{D}$ ) any one of them could be removed from hybrid E-Nose structure without affecting its performance.
The PC score of the principal components for hybrid-mono-class E-Nose is shown in Fig. 3. The obtained score of each target gas has been grouped together to understand the discrimination capability of sensor arrays toward the target gases (Fig. 3). The target gases were clearly separated into four clusters in principal component space, which indicates that the hybrid-mono E-Nose (array of 16 sensors) provides excellent discrimination ability with respect to the target gases using principal component analysis. Only six sensors (five from group of interdependent sensors and one independent sensor) are identified using PCA studies which are required to make an array for hybrid-mono class E-Nose:- $\mathrm{SnO}_{2}$-Ptcluster at $60^{\circ} \mathrm{C}, \mathrm{SnO}_{2}-\mathrm{Pt}$-cluster at $140^{\circ} \mathrm{C}, \mathrm{SnO}_{2-}$ $\mathrm{Pd}$-cluster at $60^{\circ} \mathrm{C}, \mathrm{SnO}_{2}-\mathrm{Pd}$-cluster at $140^{\circ} \mathrm{C}$ $\mathrm{SnO}_{2}$-Ag-cluster at $140^{\circ} \mathrm{C}, \mathrm{SnO}_{2}$-CuO-cluster at $60^{\circ} \mathrm{C}$

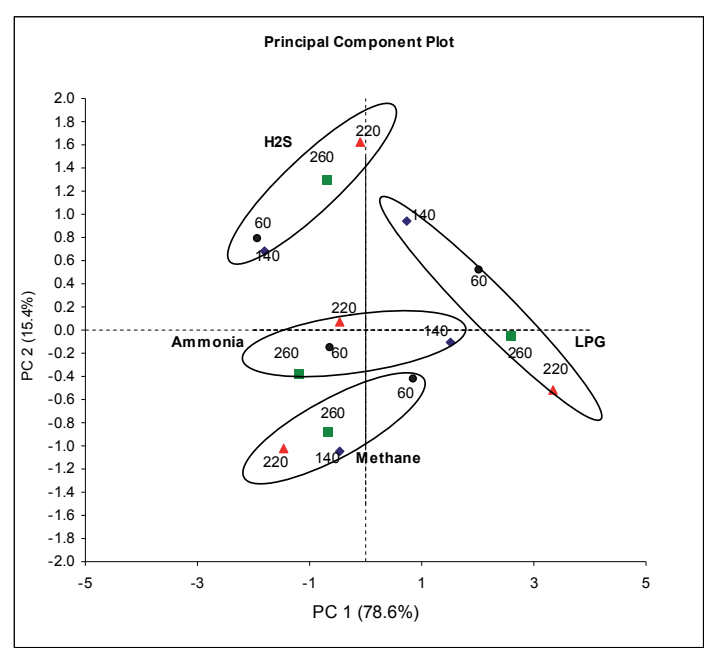

Fig. 3. The Principal Component plots for the hybrid-mono class E-Nose showing PCA score; having sixteen variables.

\section{Conclusion}

In summary, a hybrid sensor array comprising of four different sensor structures, namely, $\mathrm{SnO}_{2}-\mathrm{Pt}$-custers, $\mathrm{SnO}_{2}-\mathrm{Pd}$-clusters, $\mathrm{SnO}_{2}-\mathrm{Ag}$ clusters, $\mathrm{SnO}_{2}-\mathrm{CuO}$-clusters have been realized for identification of four target gases (LPG, $\mathrm{CH}_{4}$, $\mathrm{NH}_{3}$ and $\mathrm{H}_{2} \mathrm{~S}$ ). The pattern corresponding to all target gases has been generated and is strongly dependent on temperature.Principal component analysis of the sensing results showed great discrimination of target gases and an array of six sensors are proposed operating at lower temperature $\left(60^{\circ} \mathrm{C}\right.$ or $\left.140^{\circ} \mathrm{C}\right)$ for realization of E- Nose exhibiting good performance. 


\section{Acknowledgements}

Authors thank to Department of Science and Technology (DST), India and University of Delhi for financial support.

\section{References}

[1] D. Haridas and V. Gupta, Enhanced response characteristics of $\mathrm{SnO}_{2}$ thin film based sensors loaded with $\mathrm{Pd}$ clusters for methane detection Sens. Actuators B (2012) Article in press; doi:10.1016/j.snb.2012.02.026

[2] M. Aleixandre, I. Sayago, M.C. Horrillo, Analysis of neural networks and analysis of feature selection with genetic algorithm to discriminate among pollutant gas, Sensors and Actuators B103, 122 (2004); doi: 10.1016/j.snb.2004.04.044

[3] S Montag, M Frank, H Ulmer, D Wernet, W Gopel, Electronic nose" detects major histocompability complex-dependent prerenal and postrenal odor components, Proceedings of the Acedemy of Siences 98, 9249-9254 (2001); doi: 10.1073ypnas.161266398

[4] Gardner J W, Bartlett P N, Electronic Noses, Oxford University Press, Oxford (1999).

[5] Moseley P T, Norris J O W, Williams D E (Eds.), Techniques and Mechanisms in Gas Sensing, Adam Hilger, Bristol, 1991. 